\title{
The Teaching of Sign Language in Undergraduate Nursing Courses: A Descriptive Study as an Attribute to the Integrality of Care*
}

\author{
Wiliam César Alves Machado1\#, Carla Oliveira Shubert², Athaynne Ramos de Aguiar Prado1, \\ Edicléa Mascarenhas Fernandes ${ }^{3}$, Teresa Tonini'1, Míriam Garcia Leoni ${ }^{2}$ \\ ${ }^{1}$ Federal University of Rio de Janeiro State, Rio de Janeiro, Brazil \\ ${ }^{2}$ Estácio de Sá University, Rio de Janeiro, Brazil \\ ${ }^{3}$ Rio de Janeiro State University, Rio de Janeiro, Brazil \\ Email: "wilmachado@uol.com.br, carlashubert@yahoo.com.br, athaynne@hotmail.com, \\ professoraediclea.uerj@gmail.com,ttonini@terra.com.br,miriam.leoni@estacio.br
}

Received 21 August 2015; accepted 28 December 2015; published 31 December 2015

Copyright (C) 2015 by authors and Scientific Research Publishing Inc.

This work is licensed under the Creative Commons Attribution International License (CC BY).

http://creativecommons.org/licenses/by/4.0/

(c) (i) Open Access

\begin{abstract}
Background: Current and future generations of nurses must be prepared to communicate and properly care for deaf patients. The objective of this study is to describe how Brazilian Sign Language is taught in undergraduate Nursing courses. Method: This was a descriptive study with a qualitative approach, performed with fifteen professors from four universities, two public and two private and in the metropolitan region of Rio de Janeiro, through individual interviews with an analysis procedure guided by Content Analysis. Results: The teaching is restricted to the adoption of planned and established approaches to sign language and procedures to assess theoretical contents and practical domains sign language teaching exclusively in elective course often offered through the online platform. Conclusion: We conclude that professors are not prepared for the teaching of sign language and that curricula need to be appropriate to the demand of full and indistinct assistance to the population's needs.
\end{abstract}

\section{Keywords}

Undergraduate Nursing Programs, Communication Barriers, Deafness, Sign Language

\footnotetext{
"Study extracted from the dissertation: "The inclusion of Libras in the Nursing undergraduate curriculum: a diagnostic study about communication with deaf individuals”, presented to the Nursing Graduate Program at the Center for Biological Sciences and Health from the Federal University of Rio de Janeiro State, UNIRIO, 2014.

${ }^{\#}$ Corresponding author.
}

How to cite this paper: Machado, W.C.A., Shubert, C.O., de Aguiar Prado, A.R., Fernandes, E.M., Tonini, T. and Leoni, M.G. (2015) The Teaching of Sign Language in Undergraduate Nursing Courses: A Descriptive Study as an Attribute to the Integrality of Care. Health, 7, 1824-1832. http://dx.doi.org/10.4236/health.2015.714200 


\section{Introduction}

Currently, fostering initiatives that represent planned, executed, and evaluated teaching strategies for the communication with deaf clients in Undergraduate Nursing Programs are rare. Therefore, its fundamental importance to the nursing care and assistance is not recognized, and deaf clients are treated with less consideration than non-deaf clients although they are protected by the current legislation in Brazil.

It is essential to emphasize that the continuing fight to defend the rights of the deaf community culminated with the officialization of the Brazilian Sign Language (LIBRAS) [1], which was approved and published in the Union Official Gazette, in the form of Decree No. 5626 from December 22, 2005, which regulated law No. 10 436/02 from April 24, 2002. Since then, LIBRAS has been recognized as the legal means of communication and expression of the Brazilian deaf community [2].

Furthermore, according to the 2010 Census [3], about 45.6 million individuals in the Brazilian population experience some kind of disability, including 9.7 million hearing impaired who require being cared for with dignity by the medical profession.

This study attempts to demonstrate the need for a nursing curriculum that is comprehensive and adequate to the demands of the contemporary society, taking into account the specificities of disabled people, and in particular preparing students in undergraduate Nursing courses to communicate through LIBRAS.

Nurses must be prepared to communicate with the deaf clientele through sign language [4]-[6]. Although communication is emphasized as one of the most important basic instruments of this profession [7], courses in sign language have not been included in undergraduate nursing courses. Thus, the nursing curriculum is not consistent with guidelines proposed by the National Curriculum Guidelines for Undergraduate Nursing Program, which requires skills and competence in non-verbal language [8].

Nursing education is guided by the Pedagogical Course Project (PCP) [9], which recommends the skills and abilities required to provide complete health care. In addition, it aims at the articulation of curative and preventive dimensions, individual and collective, according to the determinations of the Curricular Guidelines, seeking interaction between teaching, research, and extension.

The National Curriculum Guidelines of the Undergraduate Nursing Program attempt to establish general critical and reflexive guidelines for nurse training, with emphasis on ethical principles, in the health-disease process in their different levels of attention, developing actions of health promotion, prevention, recovery, and rehabilitation in the perspective of integral assistance. Therefore, they assume that diverse educational content should be covered to assist everyone without distinction [10].

Government initiatives have attempted to achieve equality for people with hearing disabilities. For example, the National Policy of Hearing Health [11] was established to attend the hearing impaired population to improve hearing function and communication [12]. Thus, updating and adapting the undergraduate curriculum to include communicating with hearing impaired patients is not only fundamental, but also urgent. The achievement of an inclusive health practice in relation to the deaf clientele will be achieved when the basic understanding of sign language and cultural and linguistic particularities of the deaf community are considered essential skills that must be taught during the academic training of these professionals [13].

Article 3 of Decree No. 5626 of December 22, 2005 [14] provides that the discipline of Libras becomes a mandatory subject in the Speech Therapy curriculum of public and private education institutions. Libras may be an elective course for all other curricula in the health area; therefore, nurses, doctors, physiotherapists, and nutritionists, as well as other professionals who deal with deaf people, are not required to learn how to communicate with them.

Because of the urgent need to communicate with deaf patients, this study aims to identify how the teaching of the Brazilian Sign Language is conducted in Undergraduate Nursing Courses in the Metropolitan region of Rio de Janeiro.

\section{Material and Methods}

\subsection{Research Type}

This was a descriptive study with a qualitative approach, extracted from the master's thesis presented to the Federal University of Rio de Janeiro State, with the theoretical concept based on the National Curriculum Guidelines for Undergraduate Nursing Program. 


\subsection{Study Population}

The scenario of this study was composed of higher education institutions, two public, and two private, that regularly offer an Undergraduate Nursing Program, located in the metropolitan region of Rio de Janeiro, namely: Alfredo Pinto Nursing School from the Federal University of Rio de Janeiro State (UNIRIO), Anna Nery School of Nursing at the Federal University of Rio de Janeiro (UFRJ), Estácio de Sá University (ESTÁCIO), and Grande Rio University (UNIGRANRIO).

Fifteen active professors in Undergraduate Nursing Programs in these institutions participated in the study. These professors teach subjects related to communication in nursing education and/or work in the development of the professional practice, more properly in supervised internships in the area of primary and hospital health care.

The inclusion criteria for study participants were: being a professor active in nursing undergraduate courses in the metropolitan area of Rio de Janeiro, over 18 years old, participating in the planning and/or implementation of programs and theoretical/practical teaching contents in disciplines that approach the interaction and communication with deaf patients, and agree to voluntarily participate in the study by signing the Volunteer Informed Consent to Participation.

\subsection{Method of Data Collection}

Content Analysis proposed by Laurence Bardin.

\subsection{Tools for Data Collection}

The instrument used to collect information was a semi-structured interview that identified how the participants plan, perform, and evaluate course contents related to teaching communication through sign language to students in order to interact appropriately with clients with hearing disabilities. The interviews were conducted between October and November of 2013 in a reserved room at the universities. Interviews were recorded on an iPhone device and transcribed in full; the participants' speeches were evaluated for further analysis and categorization.

Through individual interview conducted in educational institutions according to a script containing three questions: 1) How are sign language teaching strategies planned in Nursing Undergraduate Courses? 2) What are the approaches established for the teaching on communication with deaf education in the institution?; and How are students evaluated on the contents of sign language teaching?

\subsection{Data Analysis}

The data analysis was based on Content Analysis, which has the starting point in the message, whether it be verbal (oral or written), gestural, silent, figurative, documentary or directly caused. The speeches were analyzed using content analysis proposed by Laurence Bardin [15].

Data were collected from professors at Nursing Undergraduate Courses in their work environments. Their testimonies were recorded and transcribed in full. These were subsequently submitted to the validation of participants to ensure that contents/clippings maintained the authenticity and reliability required by the method's scientific rigor.

The data analysis followed the criterion of saturation of the most relevant topics contained in the testimonies of participants and related to the investigated object, enabling the composition of themes.

According to Resolution No. 466/2012 from the National Health Council (CNS), the project was approved under opinion number 333629 by the Research Ethics Committee from UNIRIO on June 27, 2013.

\section{Results}

Three categories emerged from the data analysis: Planned approaches for teaching sign language; Imposed approaches for teaching communication to the deaf; Evaluation procedures in teaching sign language in Undergraduate Nursing Courses.

The contents of the participants' point of view were properly assigned in the following sequence.

\subsection{Category 1: Planned Approaches for Teaching Sign Language}

As observed in the speeches below, the teaching of sign language is approached in a general/superficial manner, 
not as a mandatory course in the curriculum grid, but taught as an elective course through the online platform, a virtual environment.

They approach LIBRAS as a non-mandatory discipline. (P3);

As an elective discipline. (P4);

LIBRAS online, not mandatory. (P6);

LIBRAS. It is a distance learning course. (P8);

Elective discipline. (P11);

LIBRAS online. (P12);

It is elective. (P15)

There were professors who were even unsure about the plan for the courses they teach. A demonstration of the little importance they attach to these courses is highlighted below.

I think it is a distance learning course, online. (P5);

I hear them saying they are going to attend LIBRAS. But I do not know how it is done. (P7);

I think yes. Because communication is not my field, I step away a little bit. (P10);

I am sorry, but I cannot give you this information. I do not know. (P13)

\subsection{Category 2: Imposed Approaches for Teaching Communication to the Deaf}

It is worth noting that some participants were well informed when questioned about how the teaching of sign language is conducted in the courses they teach.

The approach is in the discipline about relationships, including LIBRAS. (P2);

Only in the LIBRAS discipline. (P4);

The approach is learning at a distance. Through the virtual environment. (P11);

There are disciplines that make the general and specific approach, LIBRAS. (P12);

On the other hand, there were those who disregarded the entire curriculum and the various pedagogical strategies adopted to make teaching the contents in communication with deaf clients stimulating for students as noted below:

The approach is during the course of disciplines. We seek to address relevant topics, according to the context of the discipline in our university. But we also have the specific disciplines. (P6);

In addition to the specific disciplines in communication, we discuss this theme in the context of our areas (...)

I have to discuss this with my Department and, consequently, in our disciplines. (P14)

Some even referred to the obligation to offer the discipline.

We are obliged to offer LIBRAS. Moreover, this specific approach is only in this discipline. (P13)

Some participants expressed particularly evasive stands as observed in the speeches that follow.

As far as I know, the communication is addressed exclusively in the disciplines that relate to this theme. (P1); I think we should integrate disciplines more because they wind up isolated. (P3);

I think specifically, only in LIBRAS. (P15)

\subsection{Category 3: Evaluation Procedures in Teaching Sign Language in Undergraduate Nursing Courses}

Concerning the evaluation procedures, some teachers indicated a weak correlation between theory and practice in the teaching of communication through sign language.

These evaluations are theoretical. (P2);

These evaluations are conducted in different ways. But depending on the semester, we plan and this may be different. (P5);

It can be through a seminar, cycle of debates, and even during the assistance itself. (P6);

The evaluations are through an exam on campus even for the online courses. (P10); 
Concerning practical evaluations, the participants reported verifying how students interact with the deaf clientele or disclosed the difficulty of assessing what is not known, mastered.

In practice, we see how the student can apply the contents learned inside and outside the University. He has to communicate; it can be through sign language, writing, anyway, if he knows how to communicate. (P7);

On training, along with the patient. If he knows how to communicate. But because they learn about LIBRAS in their last semester, it is difficult to evaluate. (P11);

Conversely, there were reports showing a general range of different times to evaluate students about communicating with deaf customers.

The assessment must be made during the undergraduate courses and practical disciplines to verify how the student applies what he learned during the course of activities. (P9);

In addition to the evaluations within the disciplines themselves, the departments conduct practical trainings and this are the most appropriate moments to evaluate if the student can use basic tools of communication.

There are theoretical and practical evaluations. It depends on the time within the course. (P13)

\section{Discussions}

The study results point to the need for changes in the planning and execution of communication strategies applied to deaf patients in the curricula of Undergraduate Programs in Nursing to ensure that students are prepared to communicate, interact, and care for all people, including the deaf. Similarly, the results show that teachers are not prepared for teaching communication through sign language; therefore, educational institutions should invest in the training of their teachers preparing them for teaching communication with deaf patients.

Participant reports reveal that the planned approaches in the undergraduate nursing curriculum are not developed with respect to the recommendations of the National Health Policy for the Person with Disabilities because students may or may not choose to learn LIBRAS, which is the only way to communicate properly with the deaf clientele. The course on LIBRAS is offered through the virtual platform, as a distance learning course, and is an elective discipline as reported in the accounts of P3, P4, P6, P8, P11, P12, and P15.

According to the National Health Policy for the Person with Disabilities [16], health care for persons with disabilities should take into account that the network of health care services in this segment will always have interfaces with other public policies. Thus, the health care of persons with disabilities shall include the organization of actions and services in at least three interdependent and complementary levels of complexity: basic attention, outpatient specialized attention, and specialized outpatient and hospital attention. If one of the main guidelines of this Policy concerns the training of human resources with emphasis on integral attention to health, then LIBRAS should be taught as a mandatory subject in Undergraduate Nursing Courses.

Some participants showed uncertainty in their answers as a reflection of their little attention and/or knowledge of what is planned in the curricula of the courses they teach, as noted in the speeches of P5, P7, P10, and P13.

In a study about how the members of the nursing staff in a University hospital in Rio de Janeiro interact with deaf clients, participants reported using various improvised strategies seeking to promote the quality of assistance and care to deaf customers as a way of complementing the gap in their professional training, including those in undergraduate programs [6]. However, the quality of care and nursing care to deaf clients can be significantly improved by training nurses in LIBRAS.

Without receiving a systematic, mandatory, and regular education in LIBRAS in undergraduate courses, nurses who teach these courses do not attach the due value to the subject; nor do they show confidence in the approaches adopted in the curricula of institutions as evidenced by answers such as "I think", or even negative answers such as "I don't know".

Despite the progressive movement for the transformation of the nursing curriculum with philosophical and pedagogical concerns, a great emphasis on technical-professional competence is still prevalent at the expense of the professional's internal growth process [10]. Participant testimonies acknowledging that LIBRAS is not an important component of undergraduate nursing education agrees with this statement. However, having teachers committed to teaching LIBRAS would contribute to nursing student's professional competence and internal growth. 
Promulgated by the National Education Council Resolution CNE/Board of Higher Education CES No. 3 of November 7, 2001, the National Curriculum Guidelines for Undergraduate Nursing Program aim to ensure the training of nurses with technical expertise to become able to understand the issues of life and society, enabling them to intervene.

The Curricular Guidelines express a general orientation, sometimes generic, precisely because they are not intended to be the expression of a National Curriculum [17]-[19]. The Guidelines encourage schools to overcome conservative ideas, stiffness, and stagnation of their traditional contents and the strict requirements existing in the Minimum Curriculum, but they do not define consensus targets.

Despite the prevalence of recommendations for empowering nurses in their interaction with all customers in all contexts of practice, the participants in this study confirmed the fragility of the approaches established in courses. While P2, P4, P11, and P12 were better informed, P6 and P14 positioned themselves without knowing the entire curriculum. P13 showed knowledge about the compulsory offer of LIBRAS for students. Nevertheless, evasive responses were also identified, such as those from P1, P3, and P15.

The legal recognition of sign language assumes a legalistic requirement from the practicing health care professional to ensure effective communication in the care of deaf people. However, recent studies point to the considerable lack of preparation of health professionals in the communication process with hearing impaired patients. It is essential that health professionals build skills within the academic training to communicate effectively based on the mandatory aspect of the LIBRAS discipline for senior students in the area of health and education according to law No. 10436 of April 24, 2002 [20].

From the point of view of regulatory actions in the health sector, it is worth emphasizing that ordinance No. 2073/2004 [11], as noted in its Article 1 item II, aims to organize a line of integral care (promotion, prevention, treatment, and rehabilitation) with multidisciplinary and interdisciplinary assistance to users of the Brazilian Unified Health System (SUS). Article 3, Paragraph 7 of this legislation states that the training and continuing education of health teams involving high education-level and technical level professionals from all areas of health care, must be carried out according to the SUS guidelines and systematically offered in sites for permanent education in health.

The prevalence of many difficulties experienced by instructors who teach classes in communication with the deaf is undeniable [6]. This also applies to nursing instructors. Communication with minority groups, such as the hearing impaired community, requires the understanding of their culture. Thus, professionals remain distant from understanding the deaf as a minority group and are unprepared to accommodate their culture [21]. Participants in this study were confused and provided non-objective and evasive responses about approaches used in teaching undergraduate nursing programs at the institutions where they teach.

The reports from some participants suggested a weak relationship between theory and practice regarding the procedures used for the evaluation of educational contents in LIBRAS courses adopted by teachers in Undergraduate Nursing Courses (P2, P5, P6, and P10). P7 and P11 reported difficulties in assessing the performance of students with deaf customers in situations where the fluency in LIBRAS is critical. P9, P12, and P13 did not demonstrate knowledge on the strategies for the evaluation of students about communicating with the deaf clientele, reporting particularly ample and non-objective stands about the adopted evaluation procedures.

In the Teaching Plans of Undergraduate Nursing Courses, it is essential to consider the deaf population that uses sign language as a linguistic and cultural minority group. Notwithstanding, the trend is different because most of the courses in the health area treat deafness as a pathological condition with no acknowledgment of the deaf population as a minority group [22].

Sign language allows the deaf to interpret and produce words, phrases, and texts of the written language assuming a role similar to that played by oral communication when it comes to the appropriation of the written message by the listener in Brazil [1], China [23], Australia [24], United States [25], Netherlands [26], and Turkey [27] among other countries.

It is important to remember that Brazil is the only country that does not speak Spanish in Latin America. Still, all other Latin American countries have their distinct sign language such as the Chilean, Uruguayan, Venezuelan, Colombian, and Peruvian sign language just to name a few. There are countries with different oral languages that use the same sign language such as is the case of the United States and Canada, which use the American Sign Language (ASL) [2].

Most Brazilian deaf people exhibit difficulties in the use of the alphabetic writing, probably because of the significant distance between the sign language, over which the deaf organizes his thinking, and the alphabetic 
system created for the representation of oral languages [28].

The deaf have lived through resistance movements, seeking the recognition of their culture, trying to make themselves present as a linguistic minority even if still fragmented and divided by the group that submits to cultural hegemony [29]. Hence, investing in education and use of sign language in the context of professional training of nurses seems vital for the recognition of deafness because it is through language that we represent the world and consequently represent ourselves.

A study with nurses from hospitals in Fortaleza/Ceará report findings about difficulties in the full communication with deaf people that are similar to those identified in this study, revealing that those professionals were unsure about how to communicate with deaf patients because they did not know their language and were unable to convene important information about health. They attributed this to their lack of academic training and inexperience [7].

According to the World Health Organization (WHO), the most important consequences of hearing loss are related to hearing disability and disadvantage. The first relates to a compromised performance in the ability to use audition in daily activities such as the perception of speech and environmental sounds. The other affects the performance of the individual's activities and role in society relating to educational, social, and occupational aspirations as a result of the hearing disability [12].

It is essential to consider deafness as a difference that implies, among other things, respect for the sign language as the preferred access to knowledge and the communication tool of the deaf. Thus, deaf people represent communities sharing the same language, cultural values, habits, and modes of socialization [19], interacting on a daily basis in a communicative, effective, and efficient process [30].

Immense difficulties are seen during interactions in most public and private health services when it comes to communication between professionals and people with hearing disabilities. These difficulties originate from the neglect of basic principles taught in courses for training health professionals in which communication is considered an essential tool in various health procedures [4]. This outcome perpetuates the communication barriers between two different languages, the sign and oral languages, negatively compromising the quality of care offered to the deaf population.

Important progress has been observed after almost one decade since the approval of the National Nursing Curriculum Guidelines in Brazil, particularly regarding the construction/reconstruction of the Pedagogical Projects of Undergraduate Nursing Courses [10]. However, many challenges still need to be overcome to transform the education of future health professionals, in particular, the inclusion of approaches to health care for minority groups such as members of the deaf community.

\section{Conclusions}

The data produced in this study indicate that teachers of Undergraduate Nursing Courses know the requirement of the law governing the teaching of LIBRAS. However, they are indifferent to how it is being taught in the institutions where they teach. If this course is offered as an elective discipline for students to just acquire credits, then this is a matter that needs re-evaluation and intervention.

Responses such as "I think" leads to a misleading understanding of non-commitment, as if the responsibility is of someone else, however, who is this someone else if not we, the teachers in these programs?

The need for prepared teachers to teach students to interact with and care for all patients, including the deaf clientele, is pressing for nursing education to comply with the legal principles in force in Brazil.

The databases in this area of knowledge do not have various articles published on the subject despite the relevance of the study object and its demand in the current context of inclusive societies.

This study is another contribution to the elucidation of the complex field of teaching communication through sign language to Undergraduate Nursing students; it does not claim to exhaust the subject but raises attention to new investigations in other realities.

\section{Acknowledgements}

The authors are thankful to the Coordinators of the Undergraduate Nursing Programs at the universities where this study was conducted and for the opportunity to investigate how the teaching of Libras is performed in their institutions. We are also thankful to the teachers who voluntarily participated in the study and contributed with significant information for this research. 


\section{Authors' Contributions}

WCAM, COS: worked in the conception, design, data collection, analysis, and interpretation, and manuscript writing and approval of the version to be submitted. ARAP, EMF, MGL, TT: worked on data interpretation, manuscript writing, and critical review.

\section{References}

[1] Capovilla, F.C. and Rafael, W.D. (2001) Dicionário enciclopédico ilustrado trilíngue da língua de sinais brasileira. Edusp, São Paulo.

[2] Duarte, S.B.R., Chaveiro, N., de Freitas, A.R., Barbosa, M.A., Porto, C.C. and Fleck, M.P.A. (2013) Historical, Social and Cultural Aspects of the Deaf Population. História, Ciências, Saúde-Manguinhos, 20, 1713-1734. http://dx.doi.org/10.1590/S0104-597020130005000015

[3] Instituto Brasileiro de Geografia e Estatística (IBGE) (2010) Censo Demográfico: Resultados preliminares da amostra. http://censo2010.ibge.gov.br/resultados

[4] Sheppard, K. (2014) Deaf Adults and Health Care: Giving Voice to Their Stories. Journal of the American Association of Nurse Practitioners, 26, 504-510. http://dx.doi.org/10.1002/2327-6924.12087

[5] Rebouças, C.B.A., Cezario, K.G., de Oliveira, P.M.P. and Pagliuca, L.M.F. (2011) People with Physical and Sensory Deficits: Perceptions of Undergraduate Nursing Students. Acta Paulista de Enfermagem, 24, 80-86. http://dx.doi.org/10.1590/S0103-21002011000100012

[6] Machado, W.C.A., Machado, D.A., Figueiredo, N.M.A., Tonini, T., Miranda, R.S. and Oliveira, G.M.B. (2013) Sign Language: How the Nursing Staff Interacts to Take Care of Deaf Patients? Revista de Pesquisa Cuidado é Fundamental, 5, 283-292. http://www.seer.unirio.br/index.php/cuidadofundamental/article/view/2065

[7] Pagliuca, L.M.F., Fiuza, N.L.G. and Reboucas, C.B.A. (2007) Aspects of Nurses' Communication with Hearing Impaired Persons. Revista da Escola de Enfermagem da USP, 41, 411-418. http://dx.doi.org/10.1590/S0080-62342007000300010

[8] Dantas, T.R.A., Gomes, T.M.G., da Costa, T.F., de Azevedo, T.R., Brito, S.S. and Costa, K.N.F.M. (2014) Communication between the Nursing Team and People with Hearing Deficiency. Revista Enfermagem UERJ, 22, 169-174. http://www.e-publicacoes.uerj.br/index.php/enfermagemuerj/article/view/13559/10366

[9] Rodrigues, J., Zagonel, I.P.S. and Montovani, M.F. (2007) Alternatives for the Teaching Practice in the Higher Education in Nursing. Escola Anna Nery Revista de Enfermagem, 11, 313-317. http://dx.doi.org/10.1590/S1414-81452007000200020

[10] Silva, M.G., Fernandes, J.D., Teixeira, G.A.S. and Silva, R.M.O. (2010) Contemporary Formal Nursing Education Process: Challenges and Perspectives. Texto \& Contexto Enfermagem, 19, 176-184. http://dx.doi.org/10.1590/S0104-07072010000100021

[11] Brasil. Ministério da Saúde. Portaria nº 2.073 de 28 de setembro de 2004. Institui a Política Nacional de Atenção à Saúde Auditiva, Brasília [DF].

[12] de Castro, S.S., Paiva, K.M. and Cesar, C.L.G. (2012) Communication Difficulties between Individuals with Hearing Disability and Health Professionals: A Public Health Matter. Revista da Sociedade Brasileira de Fonoaudiologia, 17, 128-134. http://dx.doi.org/10.1590/S1516-80342012000200005

[13] Levino, D.A., de Souza, E.B., Cardoso, P.C., da Silva, A.C. and Carvalho, A.E.T.M. (2013) Libras in Medical Graduation: The Awakening to a New Language. Revista Brasileira de Educação Médica, 37, 291-297. http://www.scielo.br/scielo.php?script=sci_arttext\&pid=S0100-55022013000200018\&lng=pt\&nrm=iso http://dx.doi.org/10.1590/S0100-55022013000200018

[14] Brasil (BR) Decreto $n^{\circ} 5.626$ de 22 de dezembro de 2005, que Regulamenta a Lei $n^{0} 10.436$, de 24 de abril de 2002 , que dispõe sobre a Língua Brasileira de Sinais-Libras, e o art. 18 da Lei $\mathrm{n}^{0}$ 10.098, de 19 de dezembro de 2000. Publicado no DOU de 23 de dezembro de 2005.

[15] Bardin Laurence (2004) Análise de conteúdo. $3^{\mathrm{a}}$ edição, Edições 70, Lisboa.

[16] Brasil. Ministério da Saúde (MS) (2010) Secretaria de Atenção à Saúde. Departamento de Ações Programáticas Estratégicas. Política Nacional de Saúde da Pessoa com Deficiência. Editora do Ministério da Saúde, Brasília, 24 p. (Série B. Textos Básicos de Saúde)

[17] Feurwerker, L. and Almeida, M. (2003) Curricular Guidelines and Pedagogical Projects: It's Time to Act! Revista Brasileira de Enfermagem, 56, 351-352. http://dx.doi.org/10.1590/S0034-71672003000400006

[18] Pinto, J.B.T. and Pepe, A.M. (2007) Nursing Education: Contradictions and Challenges of Pedagogical Practice. Revista Latino-Americana de Enfermagem, 15, 120-126. http://dx.doi.org/10.1590/S0104-11692007000100018 
[19] Moretti-Pires, R.O. and Bueno, S.M.V. (2009) Nursing Faculty-Student Relationship and Issues in the Education of Nurses for the Brazilian Universal Healthcare System. Acta Paulista de Enfermagem, 22, 645-651. http://dx.doi.org/10.1590/s0103-21002009000500008

[20] Bentes, I.M.S., Vidal, E.C.F. and Maia, E.R. (2011) Deaf Person’s Perception on Health Care in a Midsize City: A Descriptive-Exploratory Study. Online Brazilian Journal of Nursing, 10. http://dx.doi.org/10.5935/1676-4285.20113210

[21] Richardson, K.J. (2014) Deaf Culture: Competencies and Best Practices. Nurse Practitioners, 39, 20-28, quiz 28-29.

[22] Chaveiro, N., Barbosa, M.A. and Porto, C.C. (2008) Literature Revision about the Attendance of Deaf Patient by Health Professionals. Revista da Escola de Enfermagem da USP, 42, 578-583. http://dx.doi.org/10.1590/S0080-62342008000300023

[23] Li, Q., Xia, S., Zhao, F. and Qi, J. (2014) Functional Changes in People with Different Hearing Status and Experiences of Using Chinese Sign Language: An fMRI Study. Journal of Communication Disorders, 50, 51-60. http://dx.doi.org/10.1016/j.jcomdis.2014.05.001

[24] Prain, M., McVilly, K.R. and Ramcharan, P. (2012) Interacting with Adults with Congenital Deaf Blindness: The Experiences of Disability Support Workers. Journal of Intellectual and Developmental Disability, 37, 27-34. http://dx.doi.org/10.3109/13668250.2012.647808

[25] Garberoglio, C.L., Gobble, M.E. and Cawthon, S.W. (2012) A National Perspective on Teachers’ Efficacy Beliefs in Deaf Education. Journal of Deaf Studies and Deaf Education, 17, 367-383. http://dx.doi.org/10.1093/deafed/ens014

[26] Knoors, H. and Marschark, M. (2012) Language Planning for the 21st Century: Revisiting Bilingual Language Policy for Deaf Children. Journal of Deaf Studies and Deaf Education, 17, 291-305. http://dx.doi.org/10.1093/deafed/ens018

[27] Kemaloglu, Y.K. and Kemaloglu, P.Y.T. (2012) The History of Sign Language and Deaf Education in Turkey. Kulak Burun Boğaz Ihtisas Dergisi, 22, 65-76. http://dx.doi.org/10.5606/kbbihtisas.2012.013

[28] Silva, T.S.A. da and Bolsanello, M.A. (2014) Meaning Assignment to Writing by Deaf Children Who Are Users of Sign Language. Educar em Revista, No. spe-2, 129-142. http://dx.doi.org/10.1590/0104-4060.37020

[29] Gesueli, Z.M. (2006) Language and Identity: Deafness in Question. Educação and Sociedade, 27, 277-292. http://dx.doi.org/10.1590/S0101-73302006000100013

[30] Silva, A.B.P., Pereira, M.C.C., and Zanolli, M.L. (2012) Deafness: From Suspicion to Referral for Intervention. Revista Paulista de Pediatria, 30, 257-262. http://dx.doi.org/10.1590/s0103-05822012000200016

\title{
Abbreviations
}

\author{
ASL: American Sign Language \\ CNE: National Council of Education \\ CNS: National Health Council \\ ESTÁCIO: Estácio de Sá University \\ LIBRAS: Brazilian Sign Language \\ WHO: World Health Organization \\ PCP: Pedagogical Course Project \\ SUS: Brazilian Unified Health System \\ UNIRIO: Federal University of Rio de Janeiro State \\ UFRJ: Federal University of Rio de Janeiro \\ UNIGRANRIO: Grande Rio University
}

